\section{Qualidade das informações sobre aleitamento materno e alimentação complementar em sites brasileiros de profissionais de saúde disponíveis na internet}

\section{The quality of information on maternal breast feeding and complementary feeding on Brazilian internet sites available for health professionals}

Rosângela Quirino da Silva 1

Muriel Bauermann Gubert 2

1 Universidade Católica de Brasília. Q.S. 07 Lote 01 EPCT. Águas Claras, Taguatinga, DF, Brasil. CEP: 71.966- 700. E-mail: rosangelanutri5544@gmail.com

2 Universidade de Brasília. Brasília, DF, Brasil.

\begin{abstract}
Objectives:to analyze the information available on internet sites regarding maternal breast feeding and complementary feeding according to the recommendations of the Brazilian Ministry of Health.

Methods: a cross-sectional study was carried out using a sample of 103 sites for professional healthcare workers. Information was analyzed on maternal breast feeding $(M B)$ and complementary feeding $(C F)$. The information was quantified and analyzed qualitatively.

Results: the recommendations for $M B$ were: that it should be exclusive up to the $6^{\text {th }}$ month of life (64.1\%); that no water or tea should be added (31.1\%); that it should last for two years or more (36.9\%); and that bottles and/or pacifiers should not be used (33\%). For CF, the term weaning was used (30.1\%), it was recommended that solid feeding begin in the $6^{\text {th }}$ month of life $(47.9 \%)$, involving fruit pulp (11.6\%) or juice (9.7\%); and soup (14.6\%). According to the qualitative analysis, incorrect information included recommending the consumption of meat in the $12^{\text {th }}$ month of life, regular meals, the introduction of solid food in the 7 th month and the consumption of cow's milk in the $6^{\text {th }}$ month.

Conclusions: most of the information on breast feeding accords with the advice of the Brazilian Ministry of Health, but is not sufficient to encourage breast feeding. The information on complementary feeding mostly diverges from the official recommendations.
\end{abstract}

Key words Internet, Breast feeding, Supplementary feeding

\section{Resumo}

Objetivos: analisar as informações de sites da internet sobre o aleitamento materno e alimentação complementar de acordo com a adequação às recomendações do Ministério da Saúde do Brasil.

Métodos: realizado estudo transversal, com amostra de 103 sites de profissionais de saúde. Analisaram-se informações sobre aleitamento materno (AM) e alimentação complementar (AC). As informações foram quantificadas e analisadas qualitativamente.

Resultados: as recomendações relativas ao $A M$ foram: exclusivo até $6^{\circ}$ mês $(64,1 \%)$; sem água e chá $(31,1 \%)$; duração de dois anos ou mais (36,9\%); e não utilizar mamadeira e chupeta (33\%). Para a AC foi utilizada a terminologia desmame (30,1\%), recomendada a introdução alimentar no $6^{\circ}$ mês $(47,9 \%)$, introdução da primeira papa com fruta $(11,6 \%)$ ou suco (9,7\%); e a oferta de sopa $(14,6 \%)$ como refeição. Na análise qualitativa, entre as informações incorretas, constavam recomendações de consumo de carne no $12^{\circ}$ mês, horários regulares para refeições, introdução de alimentos no $7^{\circ}$ mês e consumo de leite de vaca no $6^{\circ}$ mês.

Conclusões: a maior parte das informações sobre aleitamento materno está de acordo com o preconizado pelo Ministério da Saúde, mas são insuficientes para estimular a prática do aleitamento materno. Já as informações sobre alimentação complementar na sua maioria divergem do recomendado.

Palavras-chave Internet, Aleitamento materno, Alimentação complementar 


\section{Introdução}

Os dois primeiros anos de vida são marcados pelo crescimento acelerado e o desenvolvimento que inclui habilidades de mastigação e digestão de outros alimentos, além do leite materno. Por isso a alimentação é de grande importância nessa fase, pois deficiências nutricionais ou condutas alimentares inadequadas podem prejudicar de imediato a saúde da criança e deixar sequelas futuras como atraso escolar e desenvolvimento de doenças crônicas. ${ }^{1}$

O leite materno, quando é ofertado exclusivamente, até o sexto mês de vida, é suficiente para satisfazer as necessidades nutricionais da criança e protegê-la de doenças. A partir deste período tornase necessário introduzir alimentos complementares, pois o leite materno já não supre as necessidades. Contudo recomenda-se continuar com o aleitamento materno até os dois anos de idade ou mais. 1

O uso de mamadeira e chupeta, além do consumo prematuro de água, chá e outros alimentos interferem no aleitamento materno, pois provocam uma confusão de bicos na hora de mamar no peito, dificultando a pega correta da mama, além de provocar desconforto abdominal, cólicas no bebê e aumentar o risco de doenças. ${ }^{1}$

Apesar das vantagens, a quantidade de crianças em aleitamento materno exclusivo (AME), nos seis primeiros meses de vida, está muito aquém da recomendação da Organização Mundial da Saúde (OMS) e Ministério da Saúde. ${ }^{2}$

Após os seis meses, deve-se iniciar a introdução da alimentação complementar que deve ser rica em energia, proteínas e micronutrientes, isenta de contaminação e em quantidade apropriada para a criança. ${ }^{3}$

A introdução de novos alimentos é um período vulnerável para a ocorrência de infecções, atraso no desenvolvimento e formação de hábitos alimentares inadequados que favorecem o estabelecimento de doenças crônicas. 4,5

Em estudo realizado no município de São Paulo (SP), pesquisadores verificaram que os primeiros alimentos usualmente introduzidos são a água e/ou chá e frutas. ${ }^{5} \mathrm{Em}$ outro estudo, realizado em Salvador, o consumo alimentar de crianças menores de dois anos caracterizou-se pela substituição do leite materno pelo leite de vaca acrescido de espessante e açúcar. ${ }^{6}$

As recomendações da correta introdução da alimentação complementar variam entre alguns países. A maioria dos países recomenda que o leite de vaca não deva ser introduzido antes dos doze meses de idade, mas na Dinamarca, Suécia e Canadá, ele pode ser introduzido entre nove a dez meses. ${ }^{7} \mathrm{~A}$ idade sugerida para introdução de peixes e ovos também difere consideravelmente; diversos países recomendam que possam ser introduzidos nos quatro a seis meses, enquanto outros recomendam esperar até nove ou doze meses. ${ }^{7}$

De acordo com o Comitê de Nutrição da Sociedade Européia de Gastroentorologia Pediátrica e Nutrição (ESPGAN), os alimentos considerados com potencial alergênico maior, como ovos e peixes, não devem ser inseridos na alimentação antes dos quatro meses de idade e quando introduzidos após esse período, é necessário que seja um de cada vez para se detectar o componente que gera a reação alérgica. ${ }^{7}$

Não há no guia alimentar brasileiro para crianças menores de dois anos, restrições quanto à introdução de peixe e ovo, ou seja, ele pode ser introduzido a partir do sexto mês, porém, o manual dos dez passos para uma alimentação saudável, baseado no guia, recomenda que o ovo inteiro seja oferecido apenas depois dos dez meses e até essa idade seja usada, com moderação, apenas a gema cozida, para não prejudicar a absorção de ferro dos outros alimentos. 1 Em relação ao leite de vaca, o guia não cita a idade que deve ser introduzido, pois ele trabalha com a promoção do aleitamento materno até os dois anos ou mais, a única exceção é quando a criança é impossibilitada de receber leite materno e deve receber leite de vaca. 8

Um estudo feito em Botucatu, SP, mostra que mais da metade de crianças menores de um mês, já recebiam chá e água. ${ }^{9}$ Outro estudo mostra que as crianças recebem alimentos fonte de carboidratos complexos antes do quarto mês de idade e ingerem alimentos semissólidos antes dos seis meses. Também foi observado que as carnes estão fora do padrão alimentar básico das crianças. 10

Discussões informais com as mães sugerem que poucas compreendem os perigos de ofertar a seus bebês água, chá e suco antes dos seis meses. ${ }^{11} \mathrm{O}$ consumo de frutas, sopas, outros leites e mingau predominam na alimentação de crianças de seis a doze meses. 12

Em um estudo feito para analisar a relação de amamentação, introdução de alimentação complementar e adiposidade nos Estados Unidos observouse que mães casadas, com maior escolaridade, idade e renda tendem a seguir as recomendações de amamentação e introdução de alimentação complementar. 13

A internet guarda uma enorme quantidade de informações, 14 principalmente no que se refere à saúde, amamentação e alimentação complementar. E com o estrondoso crescimento do número de páginas 
disponíveis, torna-se difícil a manutenção da qualidade de informações na rede. 14

O número de usuários na rede é grande, mas mesmo com a expansão considerável em poucos anos, este número ainda é muito pequeno se comparado ao total de habitantes no planeta. 15

As maiores proporções de pessoas que acessaram a internet, referem utilizá-la com a finalidade de educação e aprendizado. O percentual de mulheres que acessaram a internet para busca de informações foi maior do que nos homens. 16

Este estudo tem o objetivo de verificar se as informações contidas em sites da internet sobre a prática de aleitamento materno e a recomendação de introdução de alimentação complementar estão de acordo com as recomendações do Ministério da Saúde.

\section{Métodos}

Trata-se de um estudo transversal realizado entre o mês de março e maio de 2008. Foi realizada uma busca de sites relacionados à amamentação e alimentação complementar, através do mecanismo de busca "Google".

Analisaram-se apenas os sites brasileiros que estavam direcionados para usuários comuns. Foram excluídos sites que eram direcionados para profissionais de saúde.

No primeiro momento, foi feito um rastreamento para detectar as informações mais recorrentes sobre amamentação e introdução de alimentação complementar. Em média, ao lançar os descritores no mecanismo de busca, foram encontrados 335.000 sites. Após o rastreamento, selecionaram-se as variáveis a serem analisadas de acordo com essas informações mais recorrentes sobre o aleitamento materno e a introdução da alimentação complementar.

No segundo momento, analisaram-se apenas os sites referentes à introdução de alimentação complementar. Os descritores utilizados foram: "alimentação bebê", "alimentação complementar", "introdução alimentação complementar", "desmame", "desmame precoce".

Foram excluídos sites relacionados a receitas culinárias para bebês, vendas de produtos para bebê, de arquivos de fotografias, em outro idioma e artigos científicos.

Sites que fizessem alguma recomendação sobre alimentação complementar foram incluídos. Para classificar as informações, foi utilizado o guia alimentar para crianças menores de dois anos do Ministério da Saúde. 8
No terceiro momento, verificaram-se sites que abordassem a amamentação. Os descritores utilizados foram: "amamentação", "leite materno", "aleitamento materno exclusivo", "leite humano".

Foram incluídos sites que davam recomendações sobre a duração da amamentação, a oferta de água, chá ou qualquer outro alimento e a utilização de chupeta e mamadeira.

Os sites foram divididos em dois grupos: o número um (G1) são os sites leigos, sem embasamento científico, que são compreendidos pelos blogs (abreviação de webblog). São páginas utilizadas como diário pessoal e sites destinados à gestação, amamentação e alimentação de bebês. O segundo grupo (G2) são os sites que apresentam um conhecimento científico a respeito do tema, ou seja, profissionais da área de saúde; são aqueles compreendidos por sites médicos, de hospitais, maternidades, odontologia, fonoaudiologia e de nutrição.

Após selecionar os critérios de inclusão e exclusão para cada objeto de estudo foram analisados 100 sites no G1 e 103 no G2.

Após a coleta das informações mais recorrentes sobre a amamentação e alimentação complementar, estas foram quantificadas e analisadas qualitativamente.

Este artigo refere-se à pesquisa sobre os sites de profissionais com conhecimento científico (G2). Os resultados sobre as informações de sites leigos (G1) estão apresentados em outro estudo.

\section{Resultados e Discussão}

\section{Primeira parte: análise quantitativa das informações dos sites}

Foram analisados no total 103 sites científicos. Em relação ao tipo dos sites, 35 (34,0\%) eram de hospitais, $15(14,6 \%)$ de médicos, $15(14,6 \%)$ de clínicas, $13(12,6 \%)$ de nutrição, $11(10,7 \%)$ de pediatria, 8 $(7,8 \%)$ de odontologia, $5(4,8 \%)$ de maternidades e 1 $(0,9 \%)$ de fonoaudiologia.

Os achados são primeiramente apresentados para o aleitamento materno e, em seguida, para a alimentação complementar.

\section{Aleitamento materno}

As informações mais recorrentes sobre aleitamento materno disponibilizadas nos sites são apresentadas na Tabela 1 . O aleitamento materno exclusivo até o sexto mês é recomendado por $64,1 \%$ dos sites. Embora haja uma grande quantidade de sites que façam essa recomendação, a porcentagem de mães que amamentam exclusivamente até o sexto 
mês no Brasil, ainda é muito baixa, ${ }^{2}$ de acordo com o que recomenda a OMS e o Ministério da Saúde. ${ }^{8}$ De acordo com a Pesquisa Nacional de Demografia e Saúde da Criança e da Mulher (PNDS) - 2006, menos de 50\% das crianças entrevistadas com menos de dois meses de idade eram exclusivamente amamentadas, e por volta do quarto e sexto mês esse percentual decresce para apenas 15\%. ${ }^{17} \mathrm{Um}$ estudo feito sobre a prevalência do aleitamento materno realizado nas capitais brasileiras, mostra que apenas $7,7 \%$ das crianças são alimentadas exclusivamente com leite materno até seis meses. ${ }^{2}$ Em outros dois estudos, essa prevalência foi de $2,0 \%$ e $10,3 \%$, respectivamente. 18,19 No Acre, $45 \%$ dos lactentes foram desmamados antes dos seis primeiros meses de idade. 11 Esses dados são preocupantes, pois demonstram a introdução precoce de alimentos. Ainda que a maioria dos sites faça esta recomendação, ainda há muitos que a omitem, tendo em vista que se trata de sites que são envolvidos com a saúde e têm como meta a promoção desta. Além disso, estes profissionais e também a mídia têm grande influência sobre a decisão das mães em amamentar ou não seus filhos. Esse fato foi percebido em um estudo, no qual as mães, quando questionadas sobre a importância do aleitamento materno, repetiram os discursos veiculados na mídia e pelos profissionais de saúde. 20 A partir disto, é necessário que haja um empenho maior de todos os envolvidos na área de saúde para promoção do aleitamento materno exclusivo até os seis meses de vida.
A recomendação de amamentar até dois anos ou mais está presente em apenas $36,9 \%$ dos sites. Apesar da recomendação do Ministério da Saúde de amamentar a criança até dois anos ou mais, ${ }^{8}$ a quantidade de crianças que recebe o leite materno até essa idade é relativamente baixa. ${ }^{21}$ Isto é bem evidente em alguns estudos onde a porcentagem de crianças com aleitamento materno contínuo até os 24 meses variou de $4,0 \%$ a $31,6 \% .19,21-23$ Observa-se que $4,8 \%$ dos sites recomendam amamentar somente até um ano e que $58,2 \%$ omitem a informação sobre a duração do aleitamento materno, o que pode contribuir para a baixa prevalência de aleitamento materno até dois anos. A porcentagem dos que recomendam amamentar até um ano é baixa, mas se tratando de sites, este número é expressivo, uma vez que são sites nos quais as pessoas creditam confiança por se tratarem de médicos e outros profissionais de saúde. Por isso é preciso estar explícito que o que o aleitamento materno deve ocorrer até os 24 meses ou mais, para garantir que as crianças continuem a receber os benefícios do leite materno.

Apesar de quase 1/3 dos sites não recomendarem a utilização de chupetas e mamadeiras, em São Paulo, em 2002, 53,9\% das crianças menores de um mês usavam chupeta. Este estudo também encontrou uma forte associação entre o uso de chupeta e a interrupção do aleitamento materno e verificou-se também que $64,2 \%$ das crianças que utilizavam chupeta usavam mamadeira. ${ }^{24}$ Em outro estudo realizado em Porto Alegre, percebeu-se grande

\section{Tabela 1}

Informações recorrentes dos sites sobre aleitamento materno. Brasil, Março - Maio 2008.

\begin{tabular}{lcc}
\hline Informaçães & N & $\%$ \\
\hline Aleitamento materno exclusivo & & 66 \\
Com informação que AME deve durar até sexto mês & 37 & 64,1 \\
Sem informação & 35,9 & 4,8 \\
Duração do aleitamento materno & 05 & 36,9 \\
Um ano & 38 & 58,3 \\
Dois anos ou mais & 60 & 4,8 \\
Sem informação & & 33,0 \\
Recomendação do uso de mamadeira e chupeta & 05 & 62,1 \\
Sim & 34 & 64 \\
Não & & - \\
Sem informação & - & 31,1 \\
Recomenda a ingestão de água e chá nos seis primeiros meses & 32 & 68,9 \\
Sim & 71 & \\
Não & & \\
Sem informação & & \\
\hline
\end{tabular}

$\mathrm{AME}=$ aleitamento materno exclusivo 
prevalência (39\%) de crianças com uso de chupeta aos quatro meses. ${ }^{25}$ Da mesma forma, a utilização da mamadeira mostrou-se, em estudos, bastante frequente: $46,9 \%$ das crianças com 30 dias já faziam uso da mamadeira, sendo que destas, apenas 3,8\% utilizavam-na para receber leite materno ordenhado. ${ }^{26}$ Visto a interferência desses objetos na amamentação, 8 é preocupante que $4,8 \%$ dos sites de profissionais de saúde recomendem a utilização de chupeta e mamadeira e muitos omitam este tipo de informação. Isto reforça a necessidade de maior empenho dos pediatras e outros profissionais da área de saúde em esclarecer as mães sobre os malefícios da utilização de mamadeiras e chupetas, principalmente a relação dessas com o aleitamento materno, além de estimular o consumo de alimentos líquidos em copos e colheres.

Embora alguns sites $(31,1 \%)$ especifiquem que é desnecessário ingerir água e chá nos seis primeiros meses, a prevalência de ingestão desses no Brasil é elevada. ${ }^{26}$ Em Porto Alegre, 37\% das crianças com um mês recebiam chá, seguido de $9 \%$ que ingeriam água. ${ }^{26} \mathrm{Em}$ Minas Gerais essa prevalência aproximase para a ingestão de chá $(33,6 \%)$, sendo que em relação à água essa prevalência aumenta para $12 \% .23$ Em pesquisa realizada sobre os hábitos alimentares de crianças menores de um ano os resultados mostram porcentagens aproximadas aos estudos citados anteriormente, sendo que em crianças não amamentadas essa prevalência é quase o dobro quando comparada com as crianças amamentadas. 27 Como todas as outras informações mais recorrentes nos sites sobre aleitamento materno, a quantidade dos que se omitem em relação às informações é bastante relevante. Mas, no caso específico desse estudo não houve recomendação de nenhum site para oferecer água e chá ao bebê nos seis primeiros meses. Portanto é imprescindível que haja uma maior divulgação dessa informação para se obter todas as vantagens do aleitamento materno exclusivo nos seis primeiros meses.

\section{Alimentação complementar}

As informações acerca da alimentação complementar estão dispostas na Tabela 2.

No que se refere ao termo utilizado, a palavra "desmame" está presente em 30,1\% dos sites. De acordo com o Ministério da Saúde, o termo desmame deve ser evitado, pois as mães podem confundir a introdução de alimentos com a parada total do aleitamento materno. ${ }^{8}$ Logo é preciso que os sites sejam atualizados, trocando a palavra desmame pelo termo alimentação complementar, como foi averiguado em $10,7 \%$ dos sites.
Quase a metade dos sites $(47,9 \%)$ indica introduzir os alimentos a partir dos seis meses, de acordo com o que preconiza o guia. ${ }^{8}$ Em São Paulo, em média, 27,6\% das crianças menores de seis meses já recebiam suco de frutas, sopa de legumes, mingau e frutas. 28 Em outra pesquisa sobre alimentação complementar, aos seis meses, quando deveria iniciar o consumo de alimentos complementares, quase a totalidade das crianças estudadas já incluíam uma variedade de alimentos no seu regime alimentar, como mingau, frutas e verduras preparadas na forma de suco e sopa. 4

Alguns sites (10,7\%) utilizam a recomendação antiga da OMS de introduzir alimentos do quarto ao sexto mês, ${ }^{29}$ o pode levar a muitos profissionais de saúde a indicar a introdução de alimentos nessa época. Não há nenhuma vantagem em introduzir alimentos complementares em crianças no período de quatro a seis meses.29 Verifica-se, portanto, a necessidade de atualização constante dos sites e é importante que os sites que omitem esta informação promovam a introdução de alimentos complementares na época adequada.

No que se refere à introdução da papa salgada na forma de sopa, $14,6 \%$ dos sites fazem essa recomendação. De acordo com o guia, essa terminologia "sopa de legumes" não deve ser utilizada, pois passa a idéia de consistência líquida e semilíquida e essas possuem baixa densidade energética. 8 A quantidade de sites que utilizam esse termo é relativamente alta. Em uma investigação sobre as práticas alimentares de crianças de 6 a 12 meses, mostrou-se que a probabilidade de bebês de seis meses receberem sopa é de 78\%.12 Observa-se também que 5,8\% dos sites utilizam o próprio termo "alimentos líquidos" para iniciar a introdução de alimentos. A oferta de alimentos líquidos é incompatível com a capacidade gástrica da criança, porque como esses alimentos possuem baixa densidade energética, é necessário ingerir uma quantidade maior para atender às necessidades da criança. ${ }^{30}$ Em Feira de Santana demonstrou-se um alto consumo de alimentos líquidos desde o primeiro mês de vida. ${ }^{27}$ Logo, é preciso que os profissionais de saúde incorporem os termos papa ou purê na sua rotina de trabalho.

Encontra-se na mesma situação o caso da recomendação de a primeira papa introduzida ser o suco de frutas $(9,7 \%$ dos sites $)$ e a oferta deste como refeição ( $9,7 \%$ dos sites), pois é alimento líquido de baixa densidade energética como ocorre com a sopa de legumes. Em pesquisa realizada em Minas Gerais, $55,1 \%$ dos bebês antes do quarto mês já o consumiam. 23

Em relação a primeira papa introduzida, grande 
Informações recorrentes dos sites sobre alimentação complementar. Brasil, Março - Maio 2008.

\begin{tabular}{|c|c|c|}
\hline Informações & $\mathbf{N}$ & $\%$ \\
\hline \multicolumn{3}{|l|}{ Termo utilizado } \\
\hline Alimentação complementar & 11 & 10,7 \\
\hline Desmame & 31 & 30,1 \\
\hline Sem informação & 61 & 59,2 \\
\hline \multicolumn{3}{|l|}{ Idade de introdução dos alimentos (meses) } \\
\hline $4-6$ & 11 & 10,7 \\
\hline 6 & 49 & 47,9 \\
\hline Sem informação & 43 & 41,7 \\
\hline \multicolumn{3}{|l|}{ Primeira papa introduzida } \\
\hline Salgada & 03 & 2,9 \\
\hline Fruta & 05 & 4,8 \\
\hline Suco de frutas & 10 & 9,7 \\
\hline Ambas (salgada + fruta) & 12 & 11,6 \\
\hline Sem informação & 73 & 70,9 \\
\hline \multicolumn{3}{|l|}{ Oferta de suco } \\
\hline Como refeição & 10 & 9,7 \\
\hline Após as refeições & 05 & 4,8 \\
\hline Sem informação & 88 & 85,4 \\
\hline \multicolumn{3}{|l|}{ Introdução de sopa nas refeições } \\
\hline Não & - & - \\
\hline $\operatorname{Sim}$ & 15 & 14,6 \\
\hline Sem informação & 88 & 85,4 \\
\hline \multicolumn{3}{|l|}{ Usar sal nas refeições com moderação } \\
\hline $\operatorname{Sim}$ & 17 & 16,5 \\
\hline Sem informação & 86 & 83,5 \\
\hline \multicolumn{3}{|l|}{ Processamento da papa } \\
\hline Sem liquidificar e sem passar na peneira & 17 & 16,5 \\
\hline Passar apenas na peneira & 13 & 12,6 \\
\hline Sem informação & 73 & 70,9 \\
\hline
\end{tabular}

parte dos sites indicam a doce (frutas $-5 \%$, sucos de frutas $-10 \%$ ou ambos $-12 \%$ ) e apenas $2,9 \%$ aconselham iniciar com a papa salgada. De acordo com Euclydes, ${ }^{30}$ tendo em vista as principais carências encontradas nessa fase, que são valor calórico, ferro, zinco e vitamina A, o mais aconselhado é iniciar com a papa salgada. Quando se inicia a alimentação complementar com as frutas, a aceitação dos vegetais é dificultada devido à preferência da criança pelo sabor doce. 30

A oferta de suco após as refeições está presente em $4,8 \%$ dos sites. O guia alimentar para crianças menores de dois anos recomenda que quando não for possível a presença da carne nas refeições pode ser ofertado, logo após, suco de frutas ricas em vitaminas $\mathrm{C}$, para aumentar a absorção de ferro. ${ }^{1}$ Podese oferecer, no lugar o suco, a própria fruta cítrica após as refeições. ${ }^{8}$ Em relação à introdução de alimentos considerados alergênicos, houve apenas a citação de ovo e de peixe.

O peixe foi citado por cinco sites $(4,8 \%)$ e esses referiram que a introdução deveria ocorrer a partir do nono mês. De acordo com o guia alimentar para menores de dois anos, o peixe pode ser introduzido na dieta do lactente a partir do sexto mês, mesmo que seja em pequena quantidade, para que se receba o aporte adequado de ferro. ${ }^{8}$ Nos países em desenvolvimento, alimentos ricos em ferro não são consumidos em quantidades suficientes por crianças abaixo de dois anos. ${ }^{8}$ Isso fica evidente em um estudo que mostra que $85,4 \%$ das gestantes pesquisadas admitiram não ter interesse em ofertar $o$ peixe ao bebê. 31

Em relação ao ovo, dos sites que o citam, há divergências na introdução da clara. Oito sites $(7,8 \%)$ citam a inserção da clara a partir de um ano 
de idade e outros sete sites $(6,8 \%)$ a partir do nono mês. A gema foi recomendada ofertar a partir do sexto mês, de forma lenta e gradual, por $12(11,6 \%)$ sites. Observa-se que as mães mostram interesse em ofertar ovo a seus bebês ainda no primeiro ano de vida. 31

Recomenda-se que o ovo seja ofertado inteiro apenas depois dos dez meses e até essa idade devese usar apenas a gema cozida, com moderação, para não prejudicar a absorção de ferro dos outros alimentos. ${ }^{1}$ No entanto, em um estudo de revisão bibliográfica, recomenda-se que o ovo e o peixe sejam introduzidos a partir de um ano, apenas se a criança apresentar um histórico familiar importante de alergia alimentar. ${ }^{32}$ A Organização PanAmericana de Saúde (OPAS) recomenda que peixes e ovos, assim como outros alimentos, devem ser ingeridos diariamente ou frequentemente, para assegurar as necessidades nutricionais. 33 Segundo a European Society for Pediatric Gastroenterology and Nutrition (ESPGAN) não há nenhuma evidência científica convincente de que a introdução retardada de alimentos potencialmente alergênicos, tais como peixes e ovos, reduz alergia, em crianças com risco para desenvolver alergia ou não. 7 Embora haja divergências em relação a esses alimentos, o melhor é que os profissionais de saúde utilizem o bom senso e assim como em relação a todos os alimentos, recomendem que a introdução seja feita de forma lenta e gradual de acordo com o que sugere o guia. ${ }^{8}$

Apenas dez sites $(9,7 \%)$ se referiram sobre o consumo de mel por lactentes, recomendando que ele deva ser ofertado apenas a partir de um ano. Essa informação é importante, pois o mel é considerado um alimento que oferece risco de contaminação por esporos de Clostridium botulinum. ${ }^{30}$ Grande quantidade de sites omite essa informação. É importante que os sites façam esta recomendação, tendo em vista que o botulismo pode levar à falência respiratória em casos mais graves. 34

A recomendação de utilizar o sal com moderação está em 16,5\% dos sites. Essa informação deveria estar presente em todos os sites, pois a criança adquire o hábito de gostar dos alimentos da mesma forma como the são oferecidos, por isso o guia alimentar para crianças menores de dois anos recomenda que desde o início a alimentação seja oferecida com pouco sal para que esse hábito perdure na vida adulta, ${ }^{8}$ evitando doenças crônicas não transmissíveis. Apesar disso, o consumo de sal iodado é importante, pois além de fornecer o iodo, facilita que a criança se adapte à alimentação da família. 1

No preparo da papinha, apenas $16,5 \%$ dos sites pesquisados sugerem que não é necessário passá-la no liquidificador e nem na peneira. ${ }^{1}$ Os sites $(12,6 \%)$ que recomendam passar a papa na peneira estão influenciando a mães a prejudicarem a ingestão de nutrientes importantes, pois esse ato modifica a consistência, tornando-a inadequada para a ingestão de nutrientes. 32

\section{Segunda parte: análise qualitativa das} informações dos sites

Aqui serão apresentadas algumas citações oriundas dos sites pesquisados, no intuito de gerar reflexão acerca da informação disponibilizada e seus potenciais prejuízos na geração de interrupção do aleitamento materno ou confusão na introdução da alimentação complementar adequada.

"Por volta de 12 meses se inicia o contato do bebê com as carnes."

Sabe-se que até os seis meses o ferro do leite materno supre as necessidades do lactente e a partir desse período é necessário complementar o ferro através de alimentos ricos nesse micronutriente. ${ }^{8}$ As carnes são as principais fontes de ferro, além de serem mais biodisponíveis do que o ferro encontrado nas fontes de origem vegetal. 8 O Ministério da Saúde preconiza a introdução das carnes a partir do sexto mês de vida. ${ }^{1}$ Tal orientação como foi disponibilizada, pode contribuir com a alta prevalência de anemia por deficiência de ferro. Percebe-se isso em estudo feito em São Paulo, no qual $41,7 \%$ das crianças pesquisadas apresentaram anemia. 22

\footnotetext{
"Deve-se iniciar (a alimentação complementar) com 10 a

20 g por dia até chegar a 100 a $150 \mathrm{~g}$."
}

Ao estabelecer quantidades, esta informação contribui para tornar a introdução de alimentos uma fase complicada para a mãe, pois ela poderá sentir-se frustrada caso o bebê não responda à expectativa de ingestão. Para o bebê é prejudicial também, visto que essa é uma fase de conhecimento de sabores e texturas e ao forçá-lo a consumir uma quantidade pré-determinada torna esse momento desagradável, o que pode repercutir em seus hábitos alimentares, inclusive na vida adulta. Por isso, preconiza-se que a quantidade de alimentos oferecidos baseie-se na aceitação da criança. ${ }^{32}$

\footnotetext{
"Para boa aceitação dos alimentos, a mãe deve procurar estabelecer uma rotina alimentar, isto é, sempre oferecer os sucos e papas em horários regulares."
} 
O estabelecimento de horários para as refeições acaba prejudicando o desenvolvimento do autocontrole da ingestão alimentar da criança, e isso pode levar a criança a rejeitar a refeição, causando frustração nos pais. Futuramente pode também levar a criança a se alimentar sem fome, o que pode levar à ingestão excessiva e ocasionar problemas com o peso. Portanto, o bebê deve receber os alimentos complementares quando demonstrar fome, seguindo a rotina alimentar da família. ${ }^{1}$

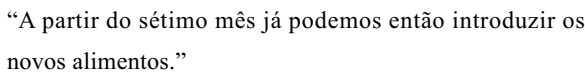

“A partir do sétimo mês já podemos então introduzir os novos alimentos."

A introdução de alimentação complementar é um período de adaptação para mãe e filho, o que muitas vezes pode gerar insegurança materna. As informações, portanto, devem ser repassadas sempre com muita clareza. Neste caso, a redação da informação pode gerar confusão. A expressão "A partir do sétimo mês" pode ser interpretada como "A partir do aniversário de sete meses" o que prorrogaria o AME por mais 30 dias. As necessidades da criança não são supridas pelo leite materno após completar seis meses de vida; a introdução tardia da alimentação pode levar a prejuízos no crescimento, risco de desnutrição e deficiência de micronutrientes. 32

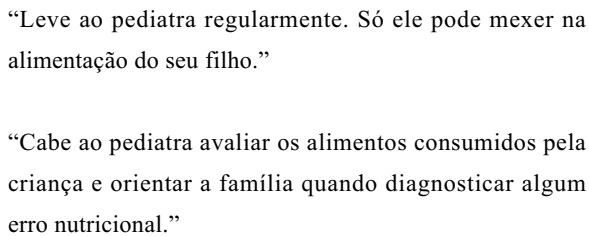

Além do acompanhamento do processo de crescimento e desenvolvimento, realizado pelo pediatra, é interessante que uma equipe interdisciplinar acompanhe a criança, para que a mesma tenha atenção integral à sua saúde. Nesta equipe, o nutricionista é também um ator importante, diagnosticando erros nutricionais e promovendo o aleitamento materno e a introdução adequada da alimentação complementar.

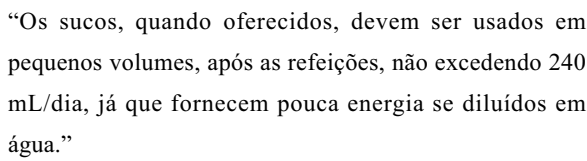

A recomendação do Ministério da saúde é que a mãe dê preferência à oferta de frutas in natura no lugar de sucos. O suco pode prejudicar a digestão e esta quantidade referida pode ser incompatível com a capacidade gástrica, tendo em vista que após o sexto mês essa capacidade é de $20-30 \mathrm{~mL} / \mathrm{kg}$ de peso e após a refeição ela se torna ainda menor. ${ }^{1}$

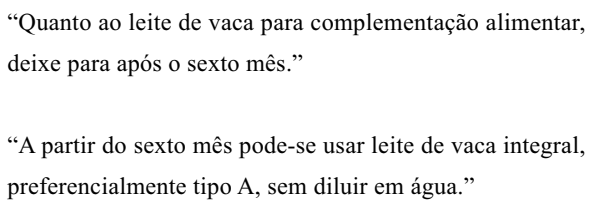

A introdução do leite de vaca não é recomendada e prejudica a duração da amamentação, que de acordo com o Ministério da Saúde deve ser de dois anos ou mais. ${ }^{8} \mathrm{~A}$ introdução do leite de vaca pode contribuir para aumentar a prevalência de anemia em crianças menores de um ano, pois estas têm necessidades elevadas de ferro em relação a outras fases de vida. 35 O leite de vaca possui baixa quantidade de ferro e este é de baixa disponibilidade, 8 além de possuir também uma grande quantidade de proteínas e minerais que interferem na absorção de ferro. 35 Acrescenta-se a isso o risco de ocorrência de microhemorragias intestinais mediante seu consumo. $36 \mathrm{O}$ leite materno é o mais adequado e ele deve ser ofertado à criança, inclusive durante a introdução a alimentação complementar, após os seis meses de vida. ${ }^{8}$

\section{Considerações finais}

De uma forma geral as informações presentes nos sites em relação à amamentação estão de acordo com o preconizado no guia alimentar para crianças menores de dois anos do Ministério da Saúde. ${ }^{8}$ As informações mais equivocadas foram as relacionadas à introdução da alimentação complementar, sendo os erros por omissão e de terminologia os mais recorrentes.

Percebe-se que o guia alimentar para crianças menores de dois anos ${ }^{8}$ ainda é utilizado de forma muito insipiente pelos profissionais de saúde, o que pode ser a causa dos equívocos encontrados.

Informações errôneas disponibilizadas em sites de profissionais de saúde têm danos potencialmente elevados, pois são julgadas corretas pelo censo comum, uma vez que os sites são elaborados por profissionais que têm um conhecimento científico sobre a promoção do aleitamento materno e introdução de alimentação complementar.

Em tempos em que a internet a tudo responde, torna-se necessário que os profissionais de saúde se engajem na promoção do aleitamento materno e introdução oportuna e adequada da alimentação complementar. A mídia, principalmente a internet, deve e pode ser utilizada para transmitir conhecimento à população, contudo de forma correta e responsável. 


\section{Referências}

1. Brasil. Ministério da Saúde. Organização Pan-Americana de Saúde. Dez passos para uma alimentação saudável. Guia alimentar para crianças menores de dois anos. Brasília, DF; 2002.

2. Sena MCF, Silva EF, Pereira MG. Prevalência do aleitamento materno nas capitais brasileiras. Rev Assoc Med Brás. 2007; 53: 520-4.

3. Giugliani ERJ, Victora CG. Alimentação complementar. J Pediatr. 2000; 76: 253-62.

4. Barbosa MB, Palma D, Bataglin T, Taddei JAAC. Custo da alimentação no primeiro ano de vida. Rev Nutr. 2007; 20: 55-62.

5. Simon VGN, Souza JMP, Souza SB. Introdução de alimentos complementares e sua relação com variáveis demográficas e socioeconômicas, em crianças no primeiro ano de vida, nascidas em Hospital Universitário no município de São Paulo. Rev Bras Epidemiol. 2003; 6: 2938.

6. Oliveira LPM, Assis AMO, Pinheiro SMC, Prado MS, Barreto ML. Alimentação complementar nos primeiros dois anos de vida. Rev Nutr. 2005; 18: 459-69.

7. Agostoni C, Decsi T, Fewtrell M, Goulet O, Kolacek S, Koletzko B, Michaelsen KF, Moreno L, Puntis J, Rigo J, Shamir R, Szajewska H, Turck D, Goudoever J. Complementary Feeding: A commentary by the ESPGHAN Committee on Nutrition. J Pediatr Gastroenterol Nutr. 2008; 46: 99-110.

8. Monte CMG, Giugliani ERJ, Carvalho MFCC, Philippi ST, Alburqueque ZP. Guia alimentar para crianças menores de dois anos. Brasília: Ministério da Saúde; 2002. 152 p. il. (Série A. Normas e Manuais Técnicos; n. 107)

9. Ferreira L, Parada CMGL, Carvalhaes MABL. Tendência do aleitamento materno em município da região centro-sul do estado de São Paulo: 1995-1999-2004. Rev Nutr. 2007; 20: 265-73.

10. Soares ND, Guimarães ARP, Sampaio HAC, Almeida PC, Colho RR. Padrão alimentar de lactentes residentes em áreas periféricas de Fortaleza. Rev Nutr. 2000; 13: 167-76.

11. Wayland C. Breastfeeding patterns in Rio Branco, Acre, Brazil: a survey of reasons for weaning. Cad Saúde Pública. 2004; 20: 1757-61.

12. Saldiva SRDM, Escuder MM, Mondini L, Levy RB, Venancio SI. Feeding habits of children aged 6 to 12 months and associated maternal factors. J Pedriatr. 2007; 83: 53-8.

13. Burdette HL, Whitaker RC, Hall WC, Daniels SR. Breastfeeding, introduction of complementary foods, and adiposity at $5 \mathrm{y}$ of age. Am J Clin Nutr. 2006; 83: 550-8.

14. Lima JC, Carvalho CL. Uma visão da web semântica. Relatório Técnico, março; 2004.

15. Monteiro L. A internet como meio de comunicação: possibilidades e limitações [dissertação]. Rio de Janeiro: Universidade Católica do Rio de Janeiro; 2001.
16. IBGE (Instituto Brasileiro de Geografia e Estatística). A pesquisa suplementar sobre acesso à internet e posse de telefone móvel celular para uso pessoal. 2005. [Acesso 22 mar 2008]. Disponível em: http://www.ibge.gov.br/home/ estatistica/populacao/acessoainternet/comentarios.pdf.

17. Ministério da Saúde. PNDS - Pesquisa Nacional de Demografia e Saúde da Criança e da Mulher. Brasília, DF, 2008.

18. Augusto RA, Souza JMP. Crescimento de crianças em aleitamento materno exclusivo no primeiro semestre de vida. Rev Bras Crescimento Desenvolv Hum. 2007; 17: 111

19. Pedroso GC, Puccini RF, Silva EMK, Silva EMK, Silva NN, Alves, MCGP. Prevalência de aleitamento materno e introdução precoce de suplementos alimentares em área urbana do Sudeste do Brasil, Embu, SP. Rev Bras Saúde Matern Infant. 2004; 4: 45-58.

20. Primo CC, Caetano LS. A decisão de amamentar da nutriz: percepção de sua mãe. J Pediatr. 1999; 75: 449-55.

21. Duarte LS, Fujimori E, Minagawa AT, Schoeps FA, Montero RMJM. Aleitamento materno e níveis de hemoglobina em crianças menores de dois anos em município do Estado de São Paulo, Brasil. Rev Nutr. 2007; 20: 149-57.

22. Silveira FJF, Lamounier JA. Prevalência do aleitamento materno e práticas de alimentação complementar em crianças com até 24 meses de idade na região do Alto Jequitinhonha, Minas Gerais. Rev Nutr. 2004; 17: 437-47.

23. Cecchetti DFA, Moura EC. Prevalência do aleitamento materno na região noroeste de Campinas, São Paulo, Brasil, 2001. Rev Nutr. 2005; 18: 201-8.

24. Cotrim LS, Venâncio SI, Escuder MML. Uso de chupeta e amamentação em crianças menores de quatro meses no estado de São Paulo. Rev Bras Saúde Matern Infant. 2002; 2: 245-52.

25. Santiago LB, Bettiol H, Barbieri MA, Guttierrez MRP, Ciampo LAD. Incentivo ao aleitamento materno: a importância do pediatra com treinamento específico. J Pediatr. 2003; 79: 504-12.

26. França MCT, Giugliani, ERJ, Oliveira LD, Weigert EML, Santo LCE, Kohler CV, Bonilha ALL. Uso de mamadeira no primeiro mês de vida: determinantes e influência na técnica de Amamentação. Rev Saúde Pública. 2008; 42: 607-14.

27. Vieira GO, Silva LR, Vieira TO, Almeida JAG, Cabral VA. Hábitos alimentares de crianças menores de um ano amamentadas e não-amamentadas. J Pediatr. 2004; 80: 4116.

28. Audi CAF, Corrêa AMS, Latorre MRDO. Alimentos complementares e fatores associados ao aleitamento materno e ao aleitamento materno exclusivo em lactentes até 12 meses de vida em Itapira, São Paulo, 1999. Rev Bras Saúde Matern Infant. 2003; 3: 85-93.

29. WHO (World Health Organization). Complementary feeding of young children in developing countries: a review of current scientific knowledge. Geneva; 1998. 
30. Euclydes MP. Nutrição do lactente: base científica para uma alimentação adequada. Viçosa: Ed Suprema Gráfica; 2000.

31. Takushi SAM, Tanaka ACA, Gallo PR, Bresolin AMB Perspectiva de alimentação infantil obtida com gestantes atendidas em centros de saúde na cidade de São Paulo. Rev Bras Saúde Matern Infant. 2006; 6: 115-25.

32. Monte CMG, Giugliani ERJ. Recomendações para alimentação complementar da criança em aleitamento materno. J Pediatr. 2004; 80: 131-41.

33. Pan American Health Organization/ World Health Organization. Guiding principles for complementary feeding of the breastfed child; 2001

Recebido em 7 de outubro de 2008

Versão final apresentada em 28 de junho de 2010

Aprovado em 5 de julho de 2010
34. Cardoso T, Costa M, Almeida HC, Guimarães M. Botulismo alimentar: estudo retrospectivo de cinco casos. Acta Méd Portuguesa. 2004; 17: 54-8.

35. Oliveira MAA, Osório MM. Consumo de leite de vaca e anemia ferropriva na infância. J Pediatr. 2005; 81: 361-7.

36. Lopez FA, Juswiak CR. O uso de fórmulas infantis após o desmame. Temas de Pediatria. Nestlé 74; 2003. 